\title{
Teaching Practice about the Post-guiding Rail Service Etiquette Course
}

\author{
Meiling XU \\ Liuzhou Railway Vocational Technical College, Liuzhou, 545007, China \\ Email: xumeiling109@163.com
}

Keywords: rail service etiquette, combination of skills and knowledge, teaching practice explore -component

\begin{abstract}
In order to make the combination of skills and knowledge, post-guiding learning is a new practical way of the current higher vocational education. The scientific attitude of the development heritage should be required. The curriculum intrinsic characteristics and the higher vocational college students' characteristics should be studied. For the course Rail Service Etiquette, a special teaching method should be created, which means putting forward drilling, training, practicing and innovating upon religious forms. It is surely important to promote the students' etiquette quality and professional quality comprehensively.
\end{abstract}

\section{Introduction}

How to carry out the course Rail Service Etiquette in higher vocational colleges? It has always been a research work. Post requirements-orientated, based on the railway service standards and with students' vocational ability training as the core is a good way. Whether they have made effective combination is a fundamental ways to examine the pertinence and effectiveness of "Rail Service Etiquette " course.

\section{Highlighting Post-orient Teaching Method Can Give New Vitality for the Course Rail Service Etiquette}

A. Highlighting post-orient teaching method is determined by the intrinsic characteristics of the course Rail Service Etiquette

"The Rail Service Etiquette" as a practical application and highly integrated science, is a course that teaches how to improve the inherent literacy and external quality of railway workers, shape the image of railway business organization or individual workers. It can cultivate the spirit of innovation and practical ability, which plays important part survival and development of rail service enterprise organizational. So it is necessary to learn this course for them.

B. Highlighting post-orient teaching method is to arouse the enthusiasm of students'practicing learning etiquette literacy

"The Rail Service Etiquette" is a required course for all students of Railway and Transportation in vocational Colleges. The enthusiasm of students is not high for learning.

Rail service etiquette courses seem easy to learn. Less time and more content enable students to produce the feeling of gulping and water off a duck's back.

How to effectively improve enthusiasm inspire for students to learn Rail Service Etiquette courses?

It needs bold reform and innovating teaching method, and taking efforts to carry out the work needs-oriented and internalized the professional etiquette literacy in the practical teaching. We should also make use of classroom to create service work scenarios, which in accordance with the service workflow. It is a task to train the students according to railway passenger services, which can cultivate the spirit of innovation and practical ability. It is featured teaching to use new teaching technology as a means of text, sound, image and media, which can increase students' interest in learning. 


\section{Building a New Curriculum System of the Course Rail Service Etiquette By Optimization}

Relying on industry, Based on Guangxi, Affecting the country, and serving the grassroots. It is School characteristics for Liuzhou Railway Vocational and Technical College.

So, the vocational the etiquette courses are designed on the actual status of the school and students and professional characteristics, and leaded by vocational education personnel training objectives.

It also is focusing on students' future workplace needs and railway characteristics. The teaching method is to build students' spirit of innovation and practical ability. The purpose of the course guides students to learn better, acquire knowledge, master the etiquette knowledge and skills better, so as to serve the railway or the community at large.

A. Highlighting the Rail service industry characteristics, make special Video, animation and case, let students participate in the ritual role-play activity so as to learn etiquette knowledge skills

Typical video can be made. The railway service etiquette covers the entire rail and subway service. In order to help students implement the service etiquette norms better, firmly establish the concept of advanced services and service awareness, understand meaning of "Good Service", and carry the team spirit, Instructional video can be made by students. The content of video comes from student graduate from our college. It helps students increase learning.interest, learn in practice, strengthen their professional ability and innovative ability. It plays a good education demonstration in the teaching process.

Typical case is featured. Typical disputes handle case can be made into a comedy and discussed in the teaching process. A real-life situation comedy video help students learn theoretical and abstract knowledge. It also guides and inspires to students master the theory, making teaching easy to be understood.

Modern information technology is used. FLASH can be directed based on advanced service concept of railway and some excellent enterprises. For example, "customer is always right" principle service is accepted. In PLASH, the moving story for dealing with tricky thing of customers also appear in front of students, which can increase students' interest for leaning and greatly enhanced the students' professionalism and professional ethics.

B. Teaching content must be scientific set, highlighting students' characteristics and meeting to students' future career development needs

"The Rail Service Etiquette" curriculum should highlight the characteristics of integrated vocational ability, and also focus on the nature of different professional and occupational characteristics. The differences refer not only the content, but also include the differences of class and teaching schedules. Students can learn as much as possible through differentiated curriculum.

Three parts of content should be set based on students' professional characteristics for railway professional and transportation professional. Especially, the content should focus on rail, subway service process service and service skills.

\section{1).Teaching modules}

- Overview

- Service concept and service awareness

- Service courtesy

- Grooming costumes specifications

-Language communication specification

- Deportment demeanor specification

- Station service jobs service specification

- Ticketing service jobs service specification

- VIP service jobs service specification

- Crew service jobs service specification

- Service of dispute prevention and treatment

2). Simulation training

- Service etiquette training

- Pioneered Good service training

- Occupational makeup techniques training 
- Honorifics Solitaire emotional communication training

- Service manners gesture training

- Dispute case processing skills training

3). Practical activities

- Participate in the voluntary service of the railway spring transportation crew, station and ticketing

- Internships

\section{Reforming and Innovation, Implementation of the "Five Words" Special Teaching in the Course Rail Service Etiquette}

The "five words" special teaching mode is adapted in the teaching process. There are Playing, Training, Case, Practice and Innovation. The "five words" teaching mode is the composition of heuristics, participatory, interactive, case-based and research-Orient method.

A. Selecting "case" and interpretation of the connotation, through case teaching, is to cultivate students' ability of analyzing and resolving problems, promoting the transformation of knowledge ability.

In case teaching, teachers are the organizers of the activities. They should choose more typical case s for students to discuss and research. They should collect some on-site service complaints and arrange them into the important etiquette teaching resources for their students to discuss. For example, in the actual teaching of the course Service Concept and Service Consciousness, some of the complaints from the railway customer service center can be used as good service etiquette material for the students to discuss and analyze

Case teaching is an important medium for the students to understand and analyze problems, which helps to improve skills to solve problem. So cases are selected taking into account authenticity and guiding values. The vivid cases are also very important. Excellent cases arouse students' interest.

B. The scene "simulation" will build a situation, which can inspire the enthusiasm of students' learning etiquette course by ritual displays

1). Role-playing pedagogy

In the etiquette teaching, classroom is set to particular occupational environment, and allowed students to play a certain role in the setting scene. So that knowledge and skills can be achieved through personal experience. Students are willing to participate in the interesting and visible activities, master of knowledge unknowingly.

2). Interview Assessment

The interview assessment can test the quality and learning outcomes. Assessment includes etiquette knowledge and job interview. Interview question come from teacher or collect from students. The interview assessment should focus on student instrument appearance, demeanor manners, polite etiquette, expression skills and adaptability, which can test and enhance the overall quality of students. Practice has proved that interview assessment teaching methods can help students increase learning.interest and improve quality of teaching.

Psychological research shows that learning any new content should seize the attention of the learners. Traditional teaching does not arouse the attention of students or excite the interest of the learners, which cause inattention, unstable or poor persistence. This affected the efficiency and quality of the teaching. Therefore, the construction of open teaching situation can greatly stimulate student motivation, and improve learning outcomes.

3). All the students Involve in the task to carry out the etiquette knowledge skills training

Task training methodology can improve the quality of students. Professional capabilities can not rely on theoretical preach sermons empty, but also depend on student participation in practice operating. The overall design of the training and teaching should meet the requirements for students' future professional positions. A topic can be put forward to students and demonstrated by teachers. Students discuss together and play a role in the training. Last, Summary of training is summarized by teachers. Interactive learning between students and teachers or students establish the dominant position of students and provide students with the training change, and then improve the students' sense of service and application service etiquette. 
4). New educational technology pedagogy, fully using new technology and new media can develop the etiquette teaching

Advanced educational technology is the mixed application of multimedia courseware. Advanced educational technology should be adapted in the teaching process. Guided by the jobs demands and aimed at internalization of professional etiquette literacy training, according to the teaching characteristics and the students' characteristics, text, sound, image and media are used for new teaching technology which can increase students' interest in learning. The multimedia courseware and the usage of the advanced education technology methods for classroom teaching can break through the difficulties and focus. The complete test can facilitate students' learning after class. The testing and learning can strengthen students' autonomous learning ability.

The author's etiquette course team is developing the multimedia courseware about the course Rail Service Etiquette, which won the First Prize in the Twelfth Session of Guangxi Colleges and Universities Education Teaching Software Technology Application Contest.

Constantly developing the network teaching resources, provides the better autonomous learning environment for the students.

We should make full use of the network, so network teaching resources are also developed to provide students with good self-learning environment. All the resources can be obtained from the web http://222.217.36.199/gzly. Making full use of network advantages will subject research results recorded in the form of web pages make the subject research electronic dynamic, and create effective autonomous learning environment for students. Thus, students can not only autonomous learning by multimedia network courseware but also deepen the learning, achieve the goal of previewing before class and reviewing after class so as to achieve the purpose of the behavior and moral character education.

\section{Learning to Practice the Application of Etiquette Teaching Can Encourage Students to Follow the Ritual}

Building a learning platform for cultivating students to apply knowledge of etiquette, form their good character, follow the ritual, this is the final aim of etiquette teaching practice. So the etiquette teaching practice link is very important. Practice teaching plays an important part in the teaching process. Traditional teaching hurt the students' interest in learning. So the etiquette courses teaching must pay close attention to the students' practical experience. Practices are in the form of internships, public service activities, volunteer service and campus culture festival. For example, Teachers allow students to participate in internships Railway Spring Festival in his spare time, which can enhance students 'practical ability to improve students' ethics, professionalism, etiquette and interpersonal skills. Also cultural activities on campus are popular for students to study and use the etiquette knowledge, to improve the etiquette quality.

\section{Conclusion}

From what has been discussed above, an etiquette teaching innovation should highlighted post-oriented teaching method, close to the railway service jobs, and focus on improving students' professional experience. Interview Assessment is a new method for testing the quality and learning outcomes. Network teaching resources will provide students with a broad learning space for the course Rail Service Etiquette, and provide platform for future career advancement services. We can say, post-guiding learning will provide more new big stage for teaching practice in high vocational colleges.

\section{References}

[1] Zhengkun JIN, Service etiquette tutorial, Renmin University of China Publishing House,2009

[2] Qun ZHOU, CBE to post-based Guidance -China's railway industry vocational education Learning from the Canadian CBE mode, Higher Education Forum, 2012.1

[3] Yansong ZHANG, four combinations in etiquette courses practice teaching for vocational college, Vocational Education Research, 2007.11

[4] Zhiying JIN, The explore of service etiquette practice teaching for cultivating the students' vocational ability, Vocational Education Research, 2008.10 